\title{
Estudos epidemiológicos: estatística é fundamental
}

\author{
Epidemiological studies: statistics is essential \\ Estudios epidemiológicos: la estadística es fundamental
}

Johnnatas Mikael Lopes. Universidade Federal do Rio Grande do Norte (UFRN). Natal, RN, Brasil. johnnataslopes2@gmail.com (Autor correspondente)

\section{Carta ao editor}

Estudar os aspectos epidemiológicos relacionados às morbidades crônicas não-transmissíveis e seus fatores de risco é muito relevante para o conhecimento das condiçóes de saúde e para a tomada de decisão sobre estratégias de controle. Esse foi o objetivo do artigo publicado por Panazzolo e colaboradores na última edição deste periódico (número 31), intitulado Prevalência de sobrepeso e obesidade em escolares do municipio de Feliz, Rio Grande do Sul. ${ }^{1}$ Entretanto, foram identificados dois equívocos no processo de análise de dados, sendo que um deles compromete a validade das conclusốes.

O primeiro dos equívocos, que não é prejudicial à validade das conclusóes, é utilizar um procedimento de estatística inferêncial para analisar informaçôes oriundas de censo populacional. É sabido que as técnicas de estatística inferencial são utilizadas para extrapolar conclusôes das amostras para a população de origem. ${ }^{2}$ Como se trata de um censo, as diferenças ou similitudes encontradas nos dados são as reais características existentes, salvo qualquer viés de informaçẫo. ${ }^{3}$ Todavia, uma explicação razoável seria que, considerando a populaçáo-alvo do estudo de 654 escolares e uma perda de 21 escolares, restando 633 participantes, este último grupo poderia ser considerado a amostra do estudo, o que levaria à necessidade de teste de hipótese.

O outro equívoco, cuja implicação pode ferir a validade das conclusóes, foi selecionar um teste de hipótese inadequado para a análise dos dados. Pelo exposto na metodologia, foi utilizado o teste $t$ independente para verificar as possíveis relaçôes entre as características dos indivíduos e da escola com o desfecho de sobrepeso/obesidade. O teste $t$, de modo simples, serve para verificar diferenças entre grupos (variável categórica) quanto a uma variável de desfecho quantitativa discreta ou contínua. ${ }^{4,5}$ Portanto, na Tabela 1, apenas seria coerente seu uso na verificação da diferença entre meninas e meninos quanto à idade (variável de desfecho contínua). Para as outras relaçôes verificadas, têm-se sempre duas variáveis categóricas, o que requer o uso de um teste de hipótese que compare as proporçôes, por exemplo, o Qui-quadrado de Pearson.

O problema mencionado acima se repete na Tabela 2, onde tentou-se identificar a relação entre a presença de sobrepeso/obesidade em meninos e meninas de acordo com o tipo de estabelecimento de ensino e sua localizaçáo. Todas as variáveis (sexo, localizaçáo, tipo de estabelecimento e presença de sobrepeso/obesidade) são do tipo categóricas.

Por fim, o mesmo equívoco do teste de hipótese ocorreu no Gráfico 1. Os autores utilizam o teste $t$ independente para comparar diferença de proporção entre os grupos etários 6-7 e 9-10 anos (variável categórica), o que é também incoerente do ponto de vista estatístico. Nesta situação, há também um erro metodológico onde não se inclui nas faixas a idade de 8 anos. Mesmo não havendo representantes desta idade na amostra, ela deve ser incluída em alguma das faixas estudadas.

Como citar: Lopes JM. Estudos epidemiológicos: estatística é fundamental. Rev Bras Med Fam

Comunidade. 2014;9(32):311-313. Disponível em: http://dx.doi.org/10.5712/rbmfc9(32)940.
Fonte de financiamento: declara não haver. Parecer CEP: não se aplica.

Conflito de interesses: declara não haver.

Recebido em: 17/05/2014. Aprovado em: 16/08/2014 
Erros como os constatados aqui podem levar à falta de validade das conclusōes. Logo, a afirmação de que a obesidade é mais prevalente na faixa etária de 6-7 anos pode não acontecer. Para solucionar e confirmar as assertivas deve ser realizado um teste de Qui-quadrado.

\section{Referências}

1. Panazzolo PR, Finimundi HC, Stoffel MOS, Simon RA, Lima MC, Costanzi CB. Prevalência de sobrepeso e obesidade em escolares do município de Feliz, Rio Grande do Sul, Brasil. Rev Bras Med Fam Comunidade. 2014;9(31):142-8. Disponível em: http://dx.doi.org/10.5712/rbmfc9(31)684

2. Lekel JF, Elmore JG, Katz DL. Epidemiologia, bioestatística e medicina preventiva. $2^{\mathrm{a}}$ ed. Porto Alegre: Artmed; 2002.

3. Medronho RA, Bloch KV. Epidemiologia. $2^{\mathrm{a}}$ ed. São Paulo: Atheneu; 2009.

4. Oliveira AG. Bioestatística, epidemiologia e investigação: teoria e aplicações. Lisboa: Lidel; 2009. 255 p.

5. Field A. Discovering statistics using spss. $2^{\mathrm{a}}$ ed. London: Sage Publication; 2005.

\section{Resposta do autor}

\section{Prezado Editor}

O trabalho objetivava avaliar o todo da população em questão no município, através de um estudo transversal na forma de um censo, podendo-se inferir os resultados como absolutos naquela população, naquele momento. Foram, então, sumarizados e descritos os atributos mais importantes através da estatística descritiva.

A utilização da estatística inferencial no estudo tem por fim dar maior robustez aos resultados, rejeitando a hipótese nula, aqui, a não diferença entre grupos comparados, excluindo-se as diferenças ao acaso.

Conforme sugerido na carta, os cálculos foram refeitos com o teste do Qui-Quadrado de Pearson, sendo os resultados apresentados a seguir:

1. A Tabela 1 objetivava caracterizar a população estudada e estimar se havia predominância de meninos (sabido que estavam em maior número no estudo) nos estabelecimentos públicos ou privados ou na sede ou interior do município. Náo houve predominância de meninos nos estabelecimentos públicos ou privados; igualmente não houve predominância de meninos na sede ou interior do município.

2. Meninos e meninas não apresentaram diferença estatiscamente significativa nas taxas de obesidade e sobrepeso.

3. Quanto às diferenças relacionadas à idade, o estudo mostrou uma maior prevalência de obesidade nas populaçóes mais jovens. Optou-se por comparar grupos nos extremos de idade, excluindo-se 126 crianças na faixa de 8 anos de idade. Após refazer os cálculos, a assertiva permanece verdadeira, tendo o grupo de crianças com 6 e 7 anos uma razáo de prevalências de 2,83 para obesidade em relaçáo às crianças de 9 e 10 anos.

Ainda, como sugerido na carta, fazendo a mesma avaliaçáo, sem que haja exclusão, dividindo a populaçáo em 2 grupos de escolares, um de menor idade (72 a 101 meses) e outro de maior idade (102 a 131 meses), permanece verdadeira a assertiva de maior taxa de obesidade no grupo mais jovem, com uma razão de prevalência de obesidade no grupo mais jovem de 2,27.

4. Houve maior prevalência de obesidade em meninos matriculados nas escolas do interior do município, com uma razão de prevalência para obesidade em meninos de escolas do interior de 1,66.

A mesma assertiva não se confirma para obesidade em meninas de escolas do interior do município, ou mesmo ambos os gêneros incluídos na análise. 


\section{Considerações finais}

De acordo com os resultados obtidos através do teste do Qui-quadrado de Pearson, concluiu-se que a metodologia empregada na análise do estudo náo influiu significativamente nos resultados encontrados.

Permanecem as mesmas assertivas feitas anteriormente relativas à questão avaliada no município de Feliz no ano de 2010.

Caxias do Sul, 22 de julho de 2014.

Atenciosamente

Paulo Ricardo Panazzolo

\section{Nota dos editores}

Esta carta ao editor motivou uma reflexão do corpo editoral da Revista Brasileira de Medicina de Família e Comunidade (RBMFC) sobre o processo de avaliação dos manuscritos que recebemos. Nesse caso específico, mesmo o manuscrito tendo passado pela avaliação por pares, não foi detectado o erro apontado por esta carta. Esse tipo de erro tem maior probabilidade de ocorrer em artigos que surgem de indagaçôes de profissionais que estão na linha de frente, sem vinculação com instituiçôes acadêmicas, e uma revista voltada para a prática da atenção primária tem que estar preparada para acolher esse tipo de artigo, que frequentemente é muito relevante ao nosso público leitor alvo. Visando a assegurar um bom padrão no relato dos artigos que publicamos, decidimos, a partir deste número, submeter todos os manuscritos com metodologia quantitativa a uma revisão editorial adicional por um de nossos editores com maior interesse em métodos quantitativos, focando na adequação das técnicas estatísticas utilizadas. Cabe ainda destacar que a RBMFC prima pela transparência dos processos editoriais e que contribuiçóes dos leitores são importantes para a melhoria do periódico.

Atenciosamente,

Michael Schmidt Duncan

Leonardo Ferreira Fontenelle

Armando Henrique Norman

Editores da RBMFC 